\title{
Determination of the band structure diagram of semiconductor heterostructures applied in photovoltaics
}

\author{
Rafat Antoni BOGACZEWICZ ${ }^{1}$, Ewa POPKO², Katarzyna Renata GWÓŹDŹ2 \\ ${ }^{1}$ Wrocław University of Science and Technology, Faculty of Fundamental Problems of Technology, \\ Wybrzeże Wyspiańskiego 27, 50-370 Wrocław, Poland \\ ${ }^{2}$ Wrocław University of Science and Technology, Faculty of Fundamental Problems of Technology, \\ Chair of Quantum Technologies, Wybrzeże Wyspiańskiego 27, 50-370 Wrocław, Poland
}

Corresponding authors: 221107@student.pwr.edu.pl (RAB), ewa.popko@pwr.edu.pl (EP), katarzyna.r.gwozdz@pwr.edu.pl (KRG)

\begin{abstract}
Recently it has been found that the heterostructures of $\mathrm{n}-\mathrm{ZnO} / \mathrm{p}$-Si are promising photovoltaic alternatives to silicon homojunctions. It is well known that the energy band diagram of a heterostructure is crucial for the understanding of its operation. This paper analyzes the $\mathrm{ZnO} / \mathrm{p}$-Si heterostructure band by using free AMPS-1D computer program simulations. The obtained numerical results are compared with theoretical calculations based on the depletion region approximation model and the Poisson's equation for electric potential. The results of the simulation are also compared with the experimental $\mathrm{C}-\mathrm{V}$ characteristics of the test $\mathrm{n}-\mathrm{ZnO} / \mathrm{p}-\mathrm{Si}$ heterostructure. The simulated $\mathrm{C}-\mathrm{V}$ characteristics is qualitatively consistent with the experimental $\mathrm{C}-\mathrm{V}$ curve, which confirms the correctness of the determined band diagram of the $\mathrm{n}-\mathrm{ZnO} / \mathrm{p}$-Si heterostructure.
\end{abstract}

Keywords: simulation, semiconductor, heterojunction, band diagram, n-ZnO/p-Si.

\section{Introduction}

Over the past two decades the photovoltaic market has developed more rapidly than presumed by the most optimistic forecasts. Nowadays homo- and heterojunctions for this purpose are produced. They are made, e.g. of $\mathrm{Si}, \mathrm{A}^{\mathrm{III}} \mathrm{B}^{\mathrm{V}}$ materials or chalcogenides. The highest solar cell efficiency is over $45 \%$ [1]. However, nowadays most commercial solar cells are based on silicon wafers. Their efficiency is about $22 \%$ [2]. Nevertheless, there is a race in search of cheaper materials and solutions.

Recently it has been shown that the heterostructures of $\mathrm{n}-\mathrm{ZnO} / \mathrm{p}-\mathrm{Si}$ are a promising photovoltaic alternative to silicon homojunctions [3] . First of all, this oxide is relatively transparent [ $\underline{4}-\underline{6}]$, therefore photons can get easily to the p-n junction. Secondly, $\mathrm{ZnO}$ conductivity is fairly high [ㄱ-10], which results in efficient photocurrent collection. 
In the study presented in this paper, the energy band diagram of the test $\mathrm{n}-\mathrm{ZnO} / \mathrm{p}-\mathrm{Si}$ heterostructure is examined. For this purpose, the AMPS-1D program is used, which was invented at the Pennsylvania State University by Professor Steven Fonash [11].

Considered heterojunction is made from semiconductors doped by one type of dopants $-\mathrm{ZnO}$ does not have any acceptors and Si has only acceptors.

The heterostructure has been made at the Institute of Physics, Polish Academy of Sciences, Warsaw. The $\mathrm{ZnO}$ layer has been grown on a commercial cheap Si substrate by means of the Atomic Layer Deposition method. Substrates were p-type silicon wafers with the resistivity of $2 \Omega \mathrm{cm}$, thickness of $180 \mu \mathrm{m}$ and orientation (100).

\section{Theoretical calculations}

\subsection{DRA model and Poisson's equation}

In the present work, a $1 \mathrm{D}$ energy band diagram of the $\mathrm{n}-\mathrm{ZnO} / \mathrm{p}$-Si heterostructure was considered. In order to obtain the band diagram of a heterojunction, it is essential to determine firstly the charge density $\rho(x)$, the electric field $E(x)$ and the electrostatic potential $V(x)$. Therefore, it was necessary to use Poisson's equation:

$$
-\frac{\mathrm{d}^{2} V(x)}{\mathrm{d} x^{2}}=\frac{\mathrm{d} E(x)}{\mathrm{d} x}=\frac{\rho(x)}{\varepsilon_{0} \varepsilon_{\mathrm{r}}}
$$

where $\varepsilon_{0}$ and $\varepsilon_{\mathrm{r}}$ denote vacuum and relative permittivity, respectively.

Charge density is expressed by the following equation:

$$
\rho(x)=q\left[p(x)-n(x)+N_{\mathrm{D}}^{+}(x)-N_{\mathrm{A}}^{-}(x)\right]
$$

Here, accordingly, $N_{\mathrm{D}}^{+}(x)$ and $N_{\mathrm{A}}^{-}(x)$ mean concentrations of ionized donors and acceptors, whereas $p(x)$ and $n(x)$ are free holes and free electron concentrations, correspondingly.

Depletion region approximation (DRA) model assumes that in the junction area there are no free electrons nor holes - the only one contribution to charge density comes from ionized dopants.

\subsection{Band diagram}

After finding electrostatic potential, it is possible to determine the band diagram of a p-n junction. At the beginning it is worth setting the level of reference at $E_{0}$ - the energy of free electron outside the electrically neutral semiconductor. Then it is possible to find the energy of local vacuum level $E_{\mathrm{L}}$ from the following equation:

$$
E_{\mathrm{L}}(x)=E_{0}+q\left(V_{\mathrm{bi}}-V(x)\right)
$$

Next relevant elements of the band diagram require knowledge of material parameters, like electron affinity $\chi(x)$ and bandgap $E_{\mathrm{G}}(x)$. The bottom of conduction band $E_{\mathrm{C}}(x)$ 
and the top of valence band $E_{\mathrm{V}}(x)$ are determined from the following equations, respectively,

$$
\begin{aligned}
& E_{\mathrm{C}}(x)=E_{\mathrm{L}}(x)-\chi(x) \\
& E_{\mathrm{V}}(x)=E_{\mathrm{C}}(x)-E_{\mathrm{G}}(x)
\end{aligned}
$$

In order to determine the Fermi level, one can take into account the n-type semiconductor (in this work - $\mathrm{ZnO}$ ) and find its bottom of conduction band $E_{\mathrm{C}}\left(x_{1}\right)$ in position $x_{1}$, where it is constant - preferably far away from the p-n junction. Then, Fermi energy is expressed as

$$
E_{\mathrm{F}}=E_{\mathrm{C}}\left(x_{1}\right)-k T \ln \left(\frac{N_{\mathrm{C}}}{n_{0}}\right)
$$

where $k$ denotes the Boltzmann constant, $T$-temperature in Kelvins, $N_{\mathrm{C}}$ is the effective density of states at the bottom of conduction band and $n_{0}$ means electron concentration in considered semiconductor before creating heterojunction. What is important, $E_{\mathrm{F}}$ is constant in the equilibrium state, and has the same value.

\subsection{Heterojunction properties}

If one wants to compare theoretical calculation with computer simulations or measurements, it will be difficult without knowledge about some heterojunction parameters. Hence we will discuss here the built-in potential $V_{\mathrm{bi}}$, junction capacitance $C$ and sizes of the $\mathrm{p}$-n junction from $\mathrm{p}$ - and n-type semiconductor, accordingly $x_{\mathrm{p}}$ and $x_{\mathrm{n}}$.

When two different semiconductors are being encountered, electrons migrate from the semiconductor with higher Fermi level to material with lower Fermi level. It results in the presence of uncompensated dopant ions and they create built-in potential. $V_{\mathrm{bi}}$ is

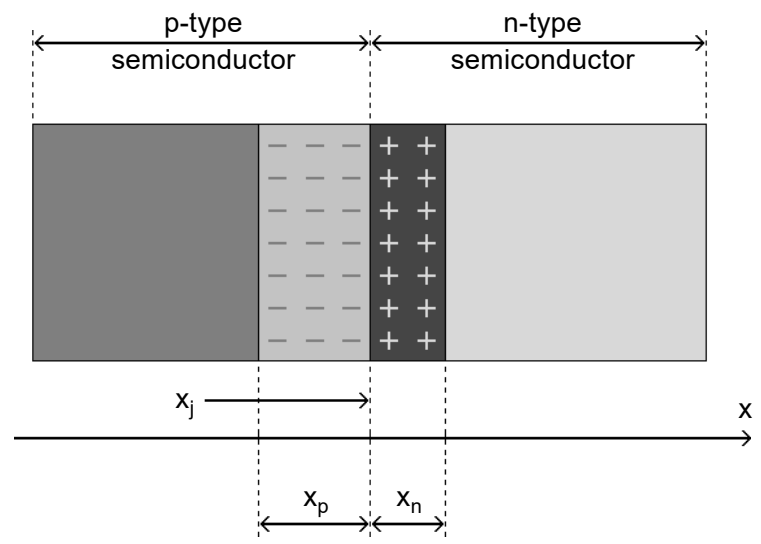

Fig. 1. P-n junction model used in theoretical calculations. Here, $x_{\mathrm{j}}$ denotes the junction position. Depletion region width is the sum of $x_{\mathrm{n}}$ and $x_{\mathrm{p}}$. Signs "+" and "-" are uncompensated acceptors and donors, respectively. 
a difference between local vacuum levels (determined at long distance from the $\mathrm{p}-\mathrm{n}$ junction) for both semiconductors. This quantity is determined from the following equation:

$$
V_{\mathrm{bi}}=k T \ln \left(\frac{N_{\mathrm{A}} N_{\mathrm{D}}}{N_{\mathrm{VP}} N_{\mathrm{CN}}}\right)+E_{\mathrm{GP}}+\chi_{\mathrm{P}}-\chi_{\mathrm{N}}
$$

where $N_{\mathrm{V}}$ is the effective density of states at the top of valence band. $N_{\mathrm{A}}$ and $N_{\mathrm{D}}$ mean acceptor and donor concentrations, correspondingly. Indexes $\mathrm{N}$ and $\mathrm{P}$ are related to the $\mathrm{n}$ - and p-type semiconductor, respectively.

According to Fig. 1, one can determine the size of a depletion region, assuming DRA model. These quantities are expressed as

$$
\begin{aligned}
& x_{\mathrm{p}}=\sqrt{\frac{2 \varepsilon_{0} \varepsilon_{\mathrm{rP}} \varepsilon_{\mathrm{rN}} N_{\mathrm{D}}\left(V_{\mathrm{bi}}-V_{\text {out }}\right)}{q N_{\mathrm{A}}\left(\varepsilon_{\mathrm{rP}} N_{\mathrm{A}}+\varepsilon_{\mathrm{rN}} N_{\mathrm{D}}\right)}} \\
& x_{\mathrm{n}}=\sqrt{\frac{2 \varepsilon_{0} \varepsilon_{\mathrm{rP}} \varepsilon_{\mathrm{rN}} N_{\mathrm{A}}\left(V_{\mathrm{bi}}-V_{\text {out }}\right)}{q N_{\mathrm{D}}\left(\varepsilon_{\mathrm{rP}} N_{\mathrm{A}}+\varepsilon_{\mathrm{rN}} N_{\mathrm{D}}\right)}}
\end{aligned}
$$

There are also indexes $\mathrm{N}$ and $\mathrm{P}$, which mean the same as in Eq. (7). $V_{\text {out }}$ is the outside voltage applied to the junction. If $V_{\text {out }}<0$, the junction will be reversed-biased.

Graphical results of theoretical calculations, assuming $N_{\mathrm{A}}>N_{\mathrm{D}}$, are presented in Fig. 2.
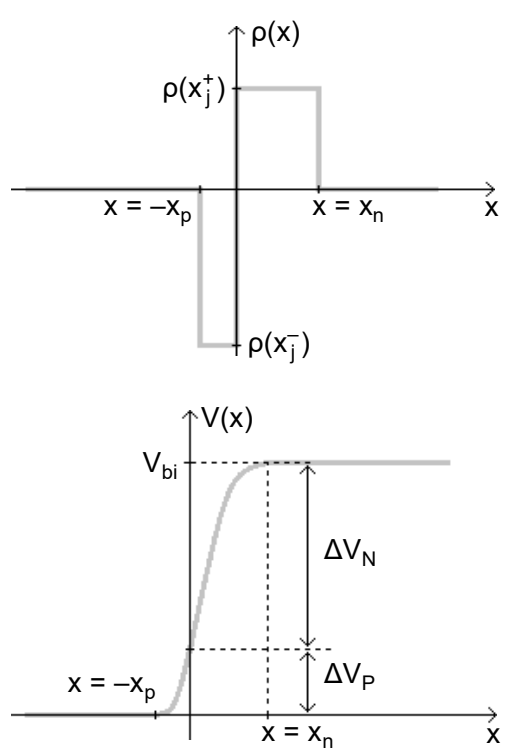

a

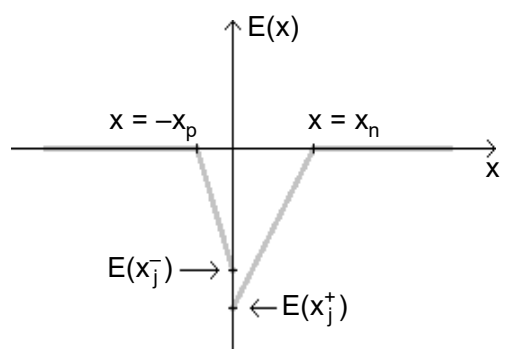

b

c

Fig. 2. Charge density $\rho(x)$ of the above-mentioned heterojunction. Here $x_{\mathrm{j}}$ is set to zero. Due to the charge conservation principle, it is easy to notice that $N_{\mathrm{A}} x_{\mathrm{p}}=N_{\mathrm{D}} x_{\mathrm{n}}(\mathbf{a})$. Electric field $E(x)$. If $\mathrm{n}$ - and p-type semiconductors are different materials, the electric field is not continuous in $x_{\mathrm{j}}(\mathbf{b})$. Electrostatic potential $V(x)$ dependences on position $x$. For both homo- and heterojunction it is continuous in $x_{\mathbf{j}}(\mathbf{c})$. 
It is important to clarify symbols in Fig. 2. Superscript at the $x_{\mathrm{j}}$, “+” or "-", means $\lim \left(x \rightarrow x_{\mathrm{j}}^{+}\right)$or $\lim \left(x \rightarrow x_{\mathrm{j}}^{-}\right)$, respectively. These quantities are expressed by the following formulas:

$$
\begin{aligned}
& \rho\left(x_{\mathrm{j}}^{+}\right)=q N_{\mathrm{D}} \\
& \rho\left(x_{\mathrm{j}}^{-}\right)=-q N_{\mathrm{A}} \\
& E\left(x_{\mathrm{j}}^{+}\right)=-\frac{q N_{\mathrm{D}} x_{\mathrm{n}}}{\varepsilon_{0} \varepsilon_{\mathrm{rN}}} \\
& E\left(x_{\mathrm{j}}^{-}\right)=-\frac{q N_{\mathrm{A}} x_{\mathrm{p}}}{\varepsilon_{0} \varepsilon_{\mathrm{rP}}} \\
& \Delta V_{\mathrm{N}}=-\frac{q N_{\mathrm{D}} x_{\mathrm{n}}^{2}}{2 \varepsilon_{0} \varepsilon_{\mathrm{rN}}} \\
& \Delta V_{\mathrm{P}}=-\frac{q N_{\mathrm{A}} x_{\mathrm{p}}^{2}}{2 \varepsilon_{0} \varepsilon_{\mathrm{rP}}}
\end{aligned}
$$

Another important parameter of the heterojunction is the capacitance $C$. It is expressed as [12]

$$
C=\sqrt{\frac{q \varepsilon_{0} \varepsilon_{\mathrm{rP}} \varepsilon_{\mathrm{rN}} S^{2} N_{\mathrm{A}} N_{\mathrm{D}}}{2\left(\varepsilon_{\mathrm{rP}} N_{\mathrm{A}}+\varepsilon_{\mathrm{rN}} N_{\mathrm{D}}\right)\left(V_{\mathrm{bi}}-V_{\text {out }}\right)}}
$$

where $S$ denotes the junction surface. Equation (16) is useful in comparing C-V characteristics and theoretical predictions. Then it is helpful to find the following quantity:

$$
\frac{\mathrm{d}}{\mathrm{d} V_{\text {out }}}\left(\frac{S^{2}}{C^{2}}\right)=-\frac{2}{q \varepsilon_{0}}\left(\frac{1}{\varepsilon_{\mathrm{rN}} N_{\mathrm{D}}}+\frac{1}{\varepsilon_{\mathrm{rP}} N_{\mathrm{A}}}\right)
$$

The slope of the $\frac{\mathrm{d}}{\mathrm{d} V_{\text {out }}}\left(\frac{S^{2}}{C^{2}}\right)$ dependence yields the concentration of $N_{\mathrm{D}}$ if $N_{\mathrm{A}}$ is known, or vice versa.

\subsection{DRA results for unbiased $\mathrm{p}-\mathrm{Si} / \mathrm{n}-\mathrm{ZnO}$ junction}

The input parameters which were used in the DRA calculations are gathered in Table 1. The electron affinity for $\mathrm{ZnO}$ was taken from Ref. [14]. In the paper, it is written that the electron affinity for $\mathrm{ZnO}$ is reported by different authors within a broad range of 3.7-5.0 eV. In our calculations we have chosen $3.7 \mathrm{eV}$. Calculations were performed for the test $\mathrm{n}-\mathrm{ZnO} / \mathrm{p}-\mathrm{Si}$ heterostructure and two others of different donor and acceptor concentrations given in Table 2. The concentration of acceptors in $\mathrm{p}$-Si for the test 
$\mathrm{T}$ a b l e 1. N-ZnO/p-Si heterojunction material parameters used in the DRA model.

\begin{tabular}{lll}
\hline Parameter & $\mathrm{p}-\mathrm{Si}$ & $\mathrm{n}-\mathrm{ZnO}$ \\
\hline$\varepsilon_{\mathrm{r}}[-]$ & $11.9[\underline{14}]$ & $8.5[\underline{13}]$ \\
$N_{\mathrm{C}}\left[\mathrm{cm}^{-3}\right]$ & $2.80 \times 10^{19}[\underline{14}]$ & $2.20 \times 10^{18}[\underline{14}]$ \\
$N_{\mathrm{V}}\left[\mathrm{cm}^{-3}\right]$ & $1.04 \times 10^{19}[\underline{14}]$ & $1.80 \times 10^{19}[\underline{14}]$ \\
$E_{\mathrm{G}}[\mathrm{eV}]$ & $1.12[\underline{14}]$ & $3.30[\underline{14}]$ \\
$\chi[\mathrm{eV}]$ & $4.05[\underline{14}]$ & $3.70[\underline{14}]$ \\
\hline
\end{tabular}

T a b l e 2. Dopant concentrations, $N_{\mathrm{A}}$ in $\mathrm{p}-\mathrm{Si}$ and $N_{\mathrm{D}}$ in $\mathrm{n}-\mathrm{ZnO}$.

\begin{tabular}{lll}
\hline Case & $N_{\mathrm{A}}\left[\mathrm{cm}^{-3}\right]$ & $N_{\mathrm{D}}\left[\mathrm{cm}^{-3}\right]$ \\
\hline I - test structure & $8.00 \times 10^{15}$ & $1.81 \times 10^{15}$ \\
II & $1.33 \times 10^{15}$ & $1.07 \times 10^{16}$ \\
\hline
\end{tabular}

$\mathrm{T}$ a b l e 3. Parameters of the calculated heterojunction in two above-mentioned cases.

\begin{tabular}{lll}
\hline Parameter & Case I & Case II \\
\hline$x_{\mathrm{n}}[\mu \mathrm{m}]$ & 0.701 & 0.120 \\
$x_{\mathrm{p}}[\mu \mathrm{m}]$ & 0.159 & 0.963 \\
$\rho\left(x_{\mathrm{j}}^{-}\right)\left[\mathrm{Ccm}^{-3}\right]$ & $-1.28 \times 10^{-3}$ & $-2.13 \times 10^{-4}$ \\
$\rho\left(x_{\mathrm{j}}^{+}\right)\left[\mathrm{Ccm}^{-3}\right]$ & $2.90 \times 10^{-4}$ & $1.71 \times 10^{-3}$ \\
$E\left(x_{\mathrm{j}}^{-}\right)\left[\mathrm{V} \mathrm{cm}^{-1}\right]$ & $-1.93 \times 10^{4}$ & $-1.95 \times 10^{4}$ \\
$E\left(x_{\mathrm{j}}^{+}\right)\left[\mathrm{V} \mathrm{cm}^{-1}\right]$ & $-2.70 \times 10^{4}$ & $-2.73 \times 10^{4}$ \\
$q V_{\mathrm{bi}}[\mathrm{eV}]$ & 1.10 & 1.10 \\
$q \Delta V_{\mathrm{N}}[\mathrm{eV}]$ & 0.95 & 0.16 \\
$q \Delta V_{\mathrm{P}}[\mathrm{eV}]$ & 0.15 & 0.94 \\
\hline
\end{tabular}

structure was assumed based on the information of the manufacturer, while the concentration of donors in the $\mathrm{ZnO}$ layer was obtained from the $\mathrm{C}-\mathrm{V}$ measurements ( $c f$. Section 4).

The most important parameters, obtained from the calculations are contained in Table 3.

Based on the above data, it can be seen that the dopant concentration, $N_{\mathrm{A}}$ and $N_{\mathrm{D}}$, has a significant impact on $x_{\mathrm{n}}$ and $x_{\mathrm{p}}$ and hence on the shape of the band diagrams.

\section{Computer simulations}

AMPS program, besides the data from Table 1, required also mobilities for electrons $\left(\mu_{\mathrm{e}}\right)$ and holes $\left(\mu_{\mathrm{h}}\right)$. For Si they are $\mu_{\mathrm{e}}=1000 \mathrm{~cm}^{2} \mathrm{~V}^{-1} \mathrm{~s}^{-1}$ and $\mu_{\mathrm{h}}=500 \mathrm{~cm}^{2} \mathrm{~V}^{-1} \mathrm{~s}^{-1}$ [14]. For $\mathrm{ZnO}$ carrier mobilities were $\mu_{\mathrm{e}}=130 \mathrm{~cm}^{2} \mathrm{~V}^{-1} \mathrm{~s}^{-1}$ and $\mu_{\mathrm{h}}=3 \mathrm{~cm}^{2} \mathrm{~V}^{-1} \mathrm{~s}^{-1}$ and they were provided by the producer of the measured sample. First of all, we modelled charge density and compared obtained results with DRA model (see Fig. 3). Later, the AMPS pro- 

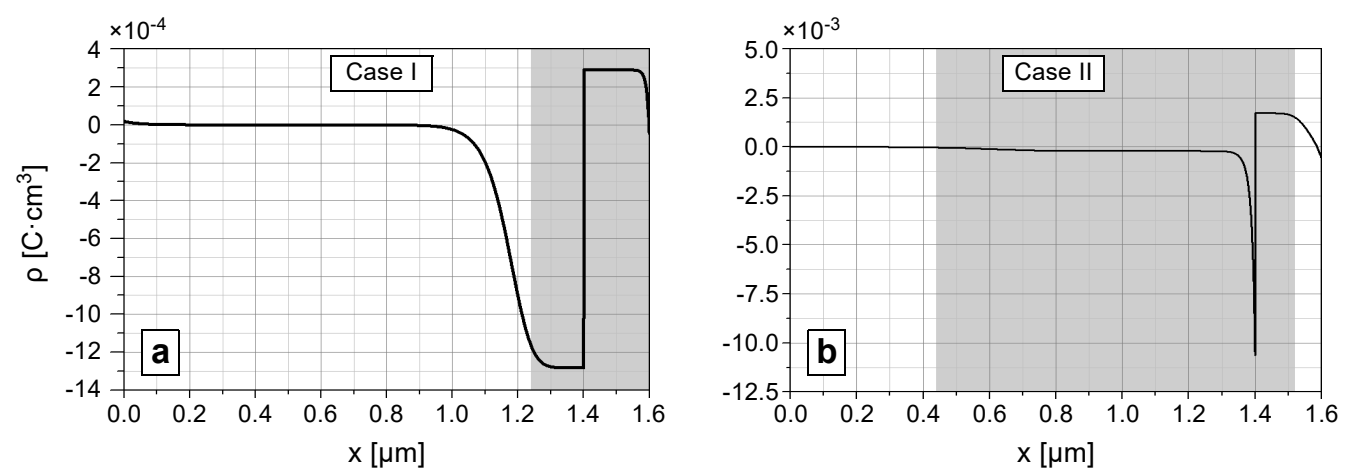

Fig. 3. Relationship between charge density $\rho$ and position $x$. Gray area depicts the theoretically determined depleted region. Here, the theoretical results are in a quite good agreement with experimental data (a). $\rho(x)$ for the second case. In this situation $\left|\rho\left(x_{\mathrm{j}}^{-}\right)\right|$is much bigger than DRA model estimations. One can observe here that different $N_{\mathrm{A}}$ and $N_{\mathrm{D}}$ from the previous situation has influence on $x_{\mathrm{n}}$ and $x_{\mathrm{p}}(\mathbf{b})$.
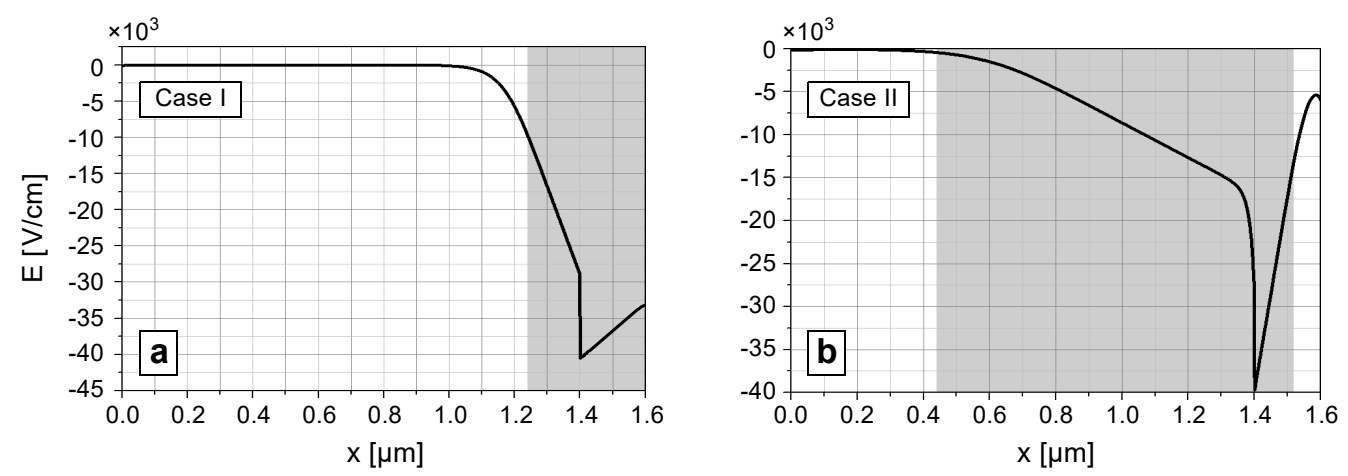

Fig. 4. Electric field in the first case. Here, like in Fig. 3a, simulations give similar results to DRA model (a); $E(x)$ for the second situation (b). Due to Eq. (1) and results from the Fig. 3b, electric field value at the interface is much bigger than the calculation based on DRA model.
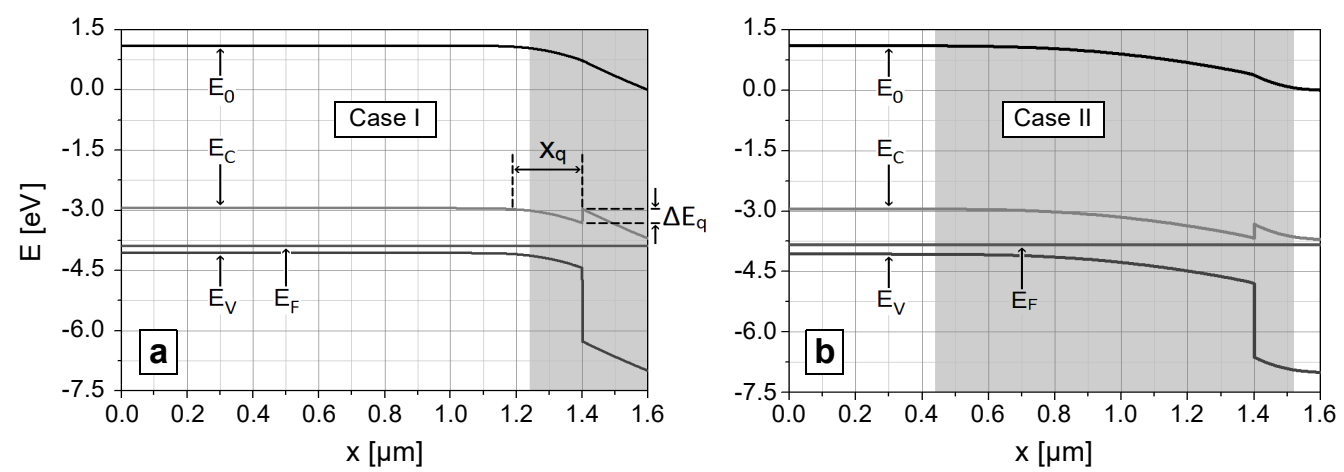

Fig. 5. Band diagram determined for the first case. One can observe here the quantum well, $x_{\mathrm{q}}$ wide and $\Delta E_{\mathrm{q}}$ deep at the bottom of the conduction band (a). Band diagram for the second case (b). 
$\mathrm{T}$ a b 1 e 4. Heterojunction parameters obtained from computer simulations.

\begin{tabular}{lll}
\hline Parameter & Case I & Case II \\
\hline$x_{\mathrm{q}}[\mu \mathrm{m}]$ & 0.21 & 0.23 \\
$\Delta E_{\mathrm{q}}[\mathrm{eV}]$ & 0.17 & 0.73 \\
$\rho\left(x_{\mathrm{j}}^{-}\right)\left[\mathrm{Ccm}^{-3}\right]$ & $-1.28 \times 10^{-3}$ & $-1.04 \times 10^{-2}$ \\
$\rho\left(x_{\mathrm{j}}^{+}\right)\left[\mathrm{Ccm}^{-3}\right]$ & $2.90 \times 10^{-4}$ & $1.71 \times 10^{-3}$ \\
$E\left(x_{\mathrm{j}}^{-}\right)\left[\mathrm{V} \mathrm{cm}^{-1}\right]$ & $-1.87 \times 10^{4}$ & $-3.08 \times 10^{4}$ \\
$E\left(x_{\mathrm{j}}^{+}\right)\left[\mathrm{V} \mathrm{cm}^{-1}\right]$ & $-2.63 \times 10^{4}$ & $-3.94 \times 10^{4}$ \\
$q V_{\mathrm{bi}}[\mathrm{eV}]$ & 1.04 & 1.10 \\
$q \Delta V_{\mathrm{N}}[\mathrm{eV}]$ & 0.93 & 0.37 \\
$q \Delta V_{\mathrm{P}}[\mathrm{eV}]$ & 0.11 & 0.73 \\
\hline
\end{tabular}

gram calculated the electric field, using received $\rho$ (Fig. 4). Finally, we band diagrams (see Fig. 5).

Moreover, AMPS program takes into account metallic contacts, contrary to theoretical calculations. Hence, it was necessary to set difference between the contact work function and the electron affinity of semiconductor.

In these simulations, refractive indexes for the front and the back contact were set to 0 and 1 , correspondingly.

One can conclude that the quantum well traps free electrons. Sometimes, like in case II, they have a big influence on the charge density and, in the face of the above, further calculations based on DRA model are entirely incorrect. To sum up, computational results are presented in Table 4.

\section{Measurements}

After getting $\mathrm{n}-\mathrm{ZnO} / \mathrm{p}-\mathrm{Si}$ sample, $\mathrm{C}-\mathrm{V}$ and $\mathrm{I}-\mathrm{V}$ measurements were carried-out. The $\mathrm{p}-\mathrm{n}$ junction cross-section (with contacts) is shown in Fig. 6.

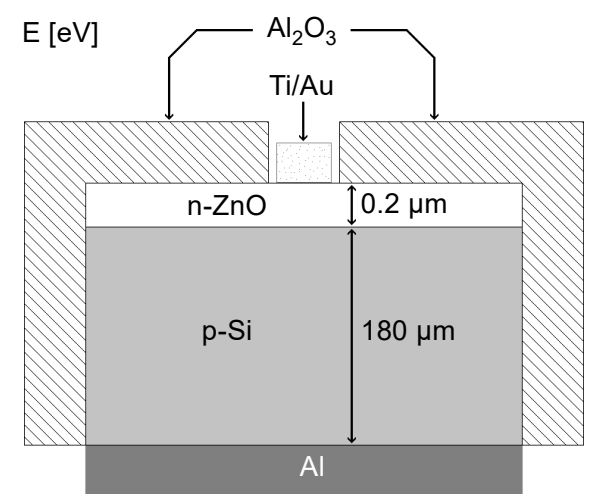

Fig. 6. Cross-section of the considered sample. Acceptor concentration in silicon, $N_{\mathrm{A}}=8.00 \times 10^{15} \mathrm{~cm}^{-3}$ was given by the manufacturer. Junction surface is $S=0.144 \mathrm{~cm}^{2}$. 

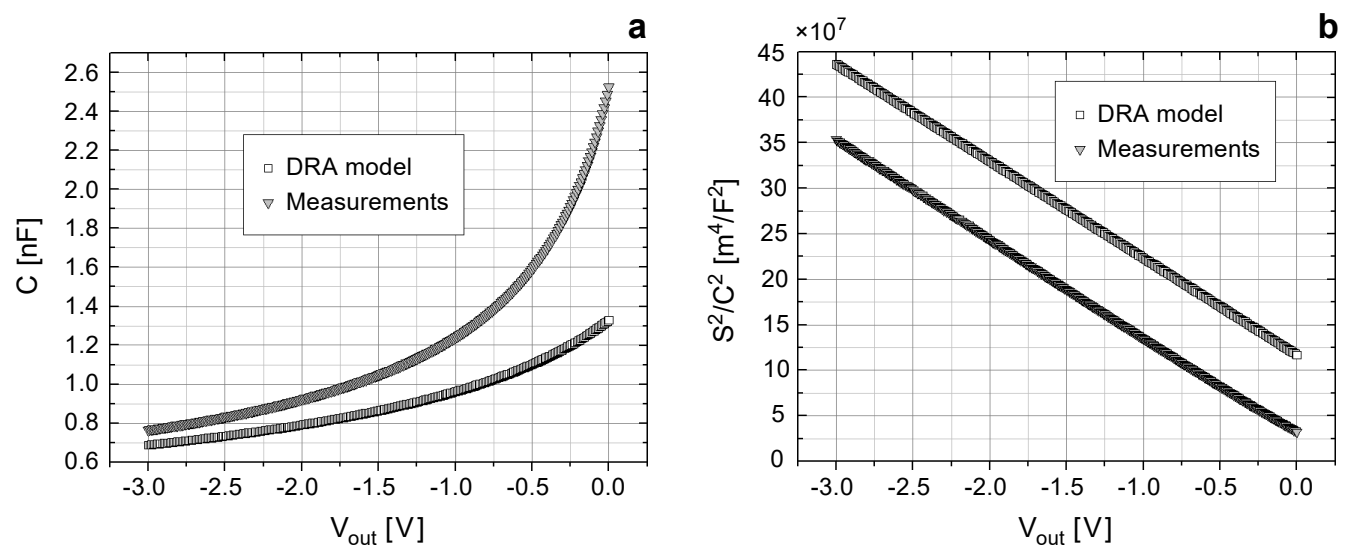

Fig. 7. C-V characteristics for theoretical calculations and measurement (a). Relationships from Eq. (17)(b). They are presented for theoretical calculations and measurements. The slope of the measured $S^{2} / C^{2} v s$. $V_{\text {out }}$ characteristics was determined as $\alpha=1.07 \times 10^{8} \mathrm{~m}^{4} \mathrm{~F}^{-2} \mathrm{~V}^{-1}$, which confirmed (due to Eq. (17)) the donor concentration as $N_{\mathrm{D}}=1.81 \times 10^{15} \mathrm{~cm}^{-3}$.

From C-V measurements (compared in Fig. 7a with results from Eq. (16)) one can confirm correctness of donor concentration, $N_{\mathrm{D}}=1.81 \times 10^{15} \mathrm{~cm}^{-3}$, assumed in theoretical calculations. First of all, it is necessary to draw dependence from Eq. (17) and find a slope coefficient $\alpha$ (see Fig. 7b). Then, transforming the above-mentioned formula, one can calculate $N_{\mathrm{D}}$.

Theoretically calculated capacitance is smaller than the measured value. This difference comes from the fact that the DRA model does not take into account the surface states at the heterojunction interface. However, the capacitance dependence on $V_{\text {out }}$ is similar in both cases.

In Fig. 8 simulated and experimental I-V characteristics are also shown. Both curves do not fit. There must be additional current transport mechanisms in a real heterostructure, like excess tunneling current due to the presence of a surface state at the $\mathrm{ZnO}-\mathrm{Si}$

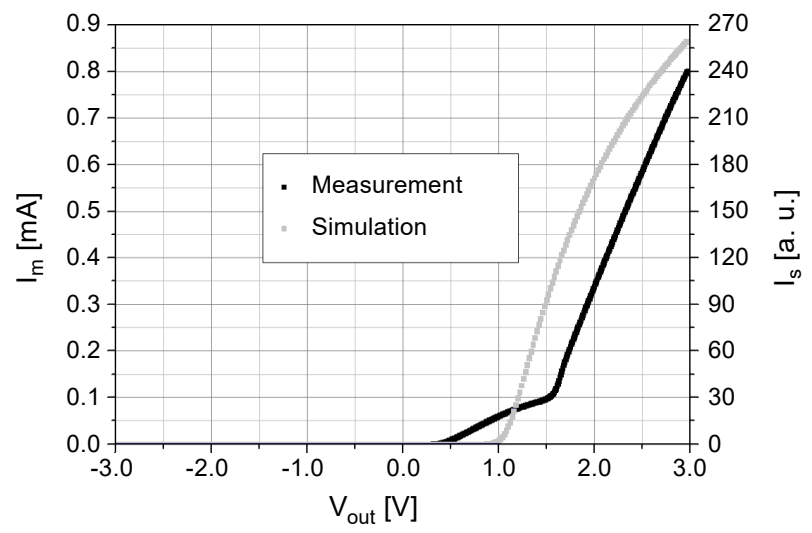

Fig. 8. I-V characteristics for a considered heterojunction. 
heterointerface. In the model, the resistivity of the ohmic contacts is neglected and this may be the reason of the experimental I-V curve shift with respect to the simulated one.

\section{Conclusions}

To sum up, a simulation of the charge density, electric field and band diagram of a test $\mathrm{n}-\mathrm{ZnO} / \mathrm{p}-\mathrm{Si}$ heterostructure has been performed. The donor concentration used in the simulation was confirmed by the $\mathrm{C}-\mathrm{V}$ measurements. Finally, the simulated I-V characteristics was compared with the measured I-V curve.

The numerical I-V characteristics based on the simulated band diagrams are qualitatively consistent with the experimental $\mathrm{C}-\mathrm{V}$ curve, therefore the determined band diagram of the studied $\mathrm{n}-\mathrm{ZnO} / \mathrm{p}-\mathrm{Si}$ heterostructure is correct.

In the considered case, the DRA model is sufficient. However, there is a possibility that in the case of a $\mathrm{n}-\mathrm{ZnO} / \mathrm{p}-\mathrm{Si}$ sample with other concentrations of dopants, the free electrons will be successfully trapped by a quantum well at the conduction band, and the above-mentioned approximation will be unsatisfactory to explain the heterostructure band diagram [15].

Acknowledgement - This work has been supported by the statutory grant of the Wroclaw University of Science and Technology, 0401/0009/17.

\section{References}

[1] https://www.nrel.gov/pv/assets/pdfs/best-research-cell-efficiencies.20190802.pdf, (accessed June 29, 2020).

[2] Descoeudres A., Holman Z.C., Barraud L., Morel S., De Wolf S., Ballif C., > 21\% efficient silicon heterojunction solar cells on $n$ - and p-type wafers compared, IEEE Journal of Photovoltaics 3(1), 2013, pp. 83-89, DOI: 10.1109/JPHOTOV.2012.2209407.

[3] Husain B., Development of n-ZnO/p-Si single heterojunction solar cell with and without interfacial layer, $\mathrm{PhD}$ Dissertation, Charlotte, 2017, available on https://coefs.uncc.edu/yzhang47/files/2018/08/ Hussain-DissertationFormatted-1.pdf, (accessed June 29, 2020).

[4] Ellmer K., Klein A., Rech B., Transparent Conductive Zinc Oxide: Basics and Applications in Thin Film Solar Cells, Springer, New York/Berloin/Heidelberg, 2007.

[5] Neumark G. F., Kuskovsky I. L., Jiang H., Optical properties of ZnO alloys, [In] Wide Bandgap Light Emitting Materials And Devices, [Ed.] Neumark G.F., Kuskovsky I.L., Jiang H., Wiley-VCH, Weinheim, 2007, p. 195.

[6] LeE J.-H., Ko K.-H., PARK B.-O., Electrical and optical properties of ZnO transparent conducting films by the sol-gel method, Journal of Crystal Growth 247(1-2), 2003, pp. 119-125, DOI: 10.1016/ S0022-0248(02)01907-3.

[7] Hiramitsu T., Furuta M., Furuta H., Matsuda T., Hirao T., Influence of thermal annealing on microstructures of zinc oxide films deposited by RF magnetron sputtering, Japanese Journal of Applied Physics 46(6R), 2007, pp. 3319-3323, DOI: 10.1143/JJAP.46.3319.

[8] Guziewicz E., Kowalik I. A., Godlewski M., Kopalko K., Osinniy V., Wojcik A., Yatsunenko S., Lusakowska E., Paszkowicz W., Guziewicz M., Extremely low temperature growth of ZnO by atomic layer deposition, Journal of Applied Physics 103(3), 2008, article 033515, DOI: 10.1063/1.2836819. 
[9] Huang J.S., Lin C.F., Influences of $\mathrm{ZnO}$ sol-gel thin film characteristics on $\mathrm{ZnO}$ nanowire arrays prepared at low temperature using all solution-based processing, Journal of Applied Physics 103(1), 2008, article 014304, DOI: $10.1063 / 1.2828172$.

[10] Lin H., Zhou S., Zhou J., Liu X., Gu S., Zhu S., Xie Z., Han P., Zhang E., Structural and optical properties of a-plane $\mathrm{ZnO}$ thin films synthesized on $\gamma-\mathrm{LiAlO}_{2}$ (302) substrates by low pressure metal -organic chemical vapor deposition, Thin Solid Films, 516(18), 2008, pp. 6079-6082, DOI: 10.1016/ j.tsf.2007.10.128.

[11] http://www.ampsmodeling.org, (accessed February 29, 2020).

[12] https://ecee.colorado.edu/ bart/book/book/chapter4/ch4_3.htm, (accessed February 29, 2020).

[13] https://www.azom.com/article.aspx?ArticleID=8417\#4, (accessed February 29, 2020).

[14] Nawaz M., Marstein E.S. Holt A., Design analysis of ZnO/cSi heterojunction solar cell, Proceedings of the 2010 35th IEEE Photovoltaic Specialists Conference, 2010, Honolulu, USA, 002213, DOI: $\underline{10.1109 / P V S C .2010 .5616070 .}$

[15] Bogaczewicz R., Determination of the band structure diagram of semiconductor heterostructures applied in photovoltaics, BSc Thesis, 2017, Wrocław, (not published).

Received April 30, 2020

in revised form July 7, 2020 